\title{
ESPACIALIDADE DO HIV E DA AIDS NO DISTRITO FEDERAL - PERÍODO DE 2012 A 2017, BRASIL
}

\section{SPATIALITY OF HIV AND AIDS IN THE FEDERAL DISTRICT - 2012 TO 2017, BRAZIL}

\author{
Ruan Italo de Araujo \\ Graduado em Geografia - Universidade de Brasília \\ Pesquisador Associado no Observatório de Territórios de Esperança - TERRES/UnB \\ ruanitalo@outlook.com
}

Rafael Rodrigues da Franca Doutor em Geografia - Universidade de Brasília Docente e Coordenador do curso de Geografia - Universidade de Brasília rrfranca@unb.br

\begin{abstract}
RESUMO
Esta pesquisa tem por objetivo compreender a espacialidade da infecção por HIV e do adoecimento por AIDS no Distrito Federal, através do georreferenciamento dos dados do Boletim Epidemiológico da Secretaria de Saúde do DF sob recorte do período 2012-2017, utilizando softwares que possibilitem essa análise geográfica. Como metodologia, optou-se pela pesquisa documental e descritiva do boletim, aplicando uma abordagem oriunda da geografia da saúde, compreendendo que diferentes contextos socioespaciais desenvolvem diferentes processos de saúde-doença, emoldurando os elementos que produzem e acentuam as vulnerabilidades dos grupos sociais frente à pandemia. Assim, torna-se possível compreender o fenômeno espacial além de sua organização e estrutura, interpretando-o de forma integrada para o desenvolvimento de um raciocínio em saúde assertivo. Os resultados deste estudo apontam uma possibilidade do aumento da infecção por HIV estar associado a regiões administrativas de classe média e média baixa, com alto potencial de interação urbana. Já em relação à AIDS, as regiões administrativas que apresentaram maior redução se configuram como de classe média alta ou alta, indicando que o processo de adoecimento não tem acontecido com a mesma intensidade nas regiões com alto índice de desenvolvimento humano.
\end{abstract}

Palavras-Chave: Espacialidade. HIV/AIDS. Geografia da Saúde. Georreferenciamento.

\begin{abstract}
This research aims to understand the spatiality of HIV infection and AIDS illness in the Federal District, through the georeferencing of data from the Epidemiological Bulletin of the Department of Health of the Federal District from 2012 to 2017 period, using software that enables this geographic analysis. This project methodology was based on the documentary and descriptive research of the chosen bulletin, applying an approach originated from health geography, understanding that different socio-spatial contexts develop different healthdisease processes, framing the elements that produce and accentuate the vulnerabilities of social groups in face of pandemic. Thus, it becomes possible to understand the spatial phenomenon beyond its organization and structure, interpreting it in an integrated way for the development of assertive health reasoning. The results of this study point to a possibility that the increase of HIV infection is associated with administrative regions of middle and lower middle class, with a high potential for urban interaction. In relation to AIDS, the administrative regions that showed the greatest reduction are configured as upper or upper middle class, indicating that the disease process has not happened with the same intensity in regions with a high human development index.
\end{abstract}

Keywords: Spatiality. HIV/AIDS. Health Geography. Georeferencing.

Recebido em: 016/12/2020

Aceito para publicação em: 06/06/2021. 


\section{INTRODUÇÃO}

A saúde é um produto social, tornando-se resultado das relações entre processos biológicos, culturais, ecológicos e socioeconômicos, segundo Mendes (1996, p.245). Essa construção do conceito de saúde é reforçada pela elaboração da I Conferência Internacional de Promoção da Saúde, constituindo a Carta de Ottawa em 1986. A presente carta afirma que os requisitos e condições para o desenvolvimento da saúde seriam educação, paz, renda, bem como o direito à moradia e à alimentação, ecossistemas estáveis, equidade e justiça social.

Portanto, nesta ampla compreensão, mais do que ausência da doença em si, a saúde seria um estado adequado de bem-estar físico, mental e social (Adriano et. al., 2000). Deste modo, a saúde ultrapassa essa percepção estática, biologicamente definida, para uma compreensão de um estado dinâmico, socialmente produzido. Por conseguinte, deve-se pensar nas esferas do cotidiano que incidem diretamente sobre a qualidade de vida da população, superando uma análise isolada, mas de fato, realizando uma prática intersetorial em saúde, incorporando o maior número possível de outras áreas como educação, trabalho, renda, meio ambiente, habitação, transporte, energia e alimentação.

O pensamento geográfico, capaz de compreender símbolos da espacialidade e da existência humana, desenvolve um olhar qualificado para identificar uma combinação de elementos que potencializam as vulnerabilidades. Aqui, entende-se que cada dimensão geográfica desenvolve seu processo de saúde-doença, compreendido por Franco Agudelo (2003, p.7-8) como "conjunto específico de condiciones y situaciones políticas, económicas, culturales, naturales y biológicas, en los cuales se hace socialmente posible y racionalmente comprensible o éticamente incomprensible la presentación de problemas de salud."

A Síndrome da Imunodeficiência Humana Adquirida (AIDS) é uma doença do sistema imunológico humano decorrente da infecção pelo Vírus da Imunodeficiência Humana (HIV), sendo a AIDS o estado avançado da doença e o HIV a infecção pelo vírus. Esta retrovirose é transmitida majoritariamente pela via sexual, onde, no avançar da doença, o vírus HIV ataca os linfócitos T CD4+, resultando numa queda de imunidade e maior vulnerabilidade da pessoa que vive com HIV, gerando riscos de contrair doenças oportunistas graves.

O Sistema Único de Saúde (SUS) desenvolvido a partir da Constituição de 1988, reflete a luta dos movimentos sociais pelo direito à saúde, tendo seus princípios fundados na equidade, na descentralização, na integração, na universalidade e no controle social (Melo; Maksud; Agostini; 2018, p.1). O SUS apresenta avanços e inovações na área de HIV e AIDS, possuindo uma série de serviços especializados como apoio psicológico, infectologistas e trabalhos transdisciplinares em áreas do cuidado à saúde. No entanto, ao realizar uma análise multiescalar, observa-se que seguindo uma tendência de urbanização e de centralização de serviços, esses equipamentos especializados localizam-se em áreas centrais, onde há uma evidente exclusão socioespacial. Contudo, novas diretrizes nacionais têm colocado a Atenção primária à Saúde (APS), também conhecida no Brasil como Atenção Básica, em posição de protagonismo nas respostas à pandemia, mantendo e ampliando ações de promoção, prevenção, diagnóstico e acompanhamento de pessoas que vivem com HIV (PVHA), destacando o Brasil em um cenário mundial (Idem, 2018, p, 2).

No Brasil, no ano de 2017, foram diagnosticados 42.420 novos casos de HIV e 37.791 de AIDS segundo o Ministério da Saúde (MS) no Boletim Epidemiológico - BE (2018, p.5), totalizando entre o período de 1980 a junho de 2018, 982.129 casos de HIV e AIDS no país. Em relação a óbito, apenas em 2017 foram registradas 11.463 mortes em consequência da AIDS.

O número de casos de HIV têm aumentado nos últimos anos, enquanto os de AIDS têm diminuído. Conforme a Secretaria de Saúde do DF (BE de HIV/AIDS, 2018, p.3), este processo deve-se fundamentalmente ao aumento da detecção precoce dos casos de HIV, antes do desenvolvimento da AIDS. De acordo com a Secretaria de Vigilância em Saúde - MS (2019, p.9), esta redução tem sido acentuada a partir da introdução do protocolo "tratamento para todos" implementado em 2013, indicando mudanças como a possibilidade de tratamento precoce para PVHA em relação sorodiscordante, bem como a expansão do uso de antirretrovirais para pessoas com contagem de linfócitos CD4 abaixo de 500 células por milímetro cúbico $\left(\mathrm{mm}^{3}\right)$, apresentando uma série de diretrizes referentes ao manejo inicial da terapia antirretroviral.

O movimento de queda da incidência da AIDS dialoga com uma série de ações de resposta à pandemia. Segundo Melo et al (2018, p.3), a introdução de novas tecnologias como a ampliação de testes rápidos em todas as regiões do país, como também as recomendações de acompanhamento 
na atenção básica fortalecem as diretrizes de promoção e prevenção, contribuindo com um diagnóstico precoce de HIV anterior ao quadro de desenvolvimento da AIDS. É possível visualizar respostas a partir dos novos protocolos, uma vez que se observa uma diminuição de $16,8 \%$ na taxa de incidência de AIDS no Brasil, saltando de 21,4/100.000 habitantes em 2012 para 17,8/100.000 habitantes em 2018 (Idem, 2019, p.9). O diagnóstico rápido da infecção é determinante para o não desenvolvimento da AIDS e de infecções oportunistas, mas também para o estado de saúde de forma mais ampla, que não compreende somente a ausência da doença, mas toda uma qualidade de vida e bem estar social das pessoas que vivem com HIV.

O aperfeiçoamento do tratamento ${ }^{2}$ provocou um impacto significativo no prognóstico e na epidemiologia da doença, como a redução de doenças oportunistas e uma tendência crescente da diminuição do coeficiente de mortalidade por AIDS, observando um decréscimo de $22,8 \%$ entre os anos 2014 e 2018 (MS, 2019, p.9).

Abordar a espacialidade do HIV e da AIDS, bem como a incidência das infecções e do processo de adoecimento, requer uma compreensão evolutiva de uma série de contingências. De acordo com Mendonça (2011, p.114), junto à vulnerabilidade socioambiental urbana, associam-se elementos sociais, políticos, econômicos, culturais, tecnológicos, aspectos que demonstram poder de intervenção na expansão ou retração de infecções e óbitos por HIV e AIDS. Uma vez relacionados, são capazes de evidenciar a exposição, fragilidades e tendências, uma análise complexa para a compreensão do fenômeno e sua gestão urbana.

No caso do DF a urbanização se constitui excludente, cria espaços que produzem e reproduzem esse processo de periferização da vida, guiando sua população para um percurso de exclusão contínua, afetando portanto, seus processos de adoecimento. O percurso dessa urbanização excludente da capital se inicia em 1959 (Paviani, 2007, p.6), quando no processo de construção surgem revoltas de trabalhadores devido a precariedade das condições de vida nos pavilhões que serviam de abrigo. A partir da consolidação desse novo espaço e do aumento da mancha urbana, o Estado passa a organizar territorialmente (em 1977 com o Plano Estrutural de Organização Territorial - PEOT) essa efervescência e o dinamismo polinucleado do DF, fundamentado em: a) especulação imobiliária; b) construção de mansões, hospitais e hotéis; c) utilização da terra como mercadoria. De forma simultânea, o Estado passa a gerir todos esses processos enquanto configuração da segregação socioespacial, gerando uma favelização das áreas não centrais como política de Estado.

A partir de 1990 as ocupações de terra por favelas ou novos assentamentos ganham força, indicando que o aumento populacional, além de servir aos objetivos da metrópole que busca mão de obra barata, fortalece um movimento de luta pela terra e pela cidade em diversos formatos: manifestações, ocupações, invasões, etc. Ainda com Paviani (2007, p.11), este período contemporâneo evidencia uma crucial política de Estado, constituindo-se como "limpeza" de áreas faveladas do Plano Piloto. Essa tendência de expulsão dos moradores empobrecidos para as periferias revela uma segregação através da periferização espacial, aumentando significativamente assentamentos no Riacho Fundo 1 e 2, Santa Maria, Recantos das Emas, nas expansões urbanas da Ceilândia e demais vilas em Sobradinho, Planaltina e Brazlândia. Regiões como Estrutural e Itapoã marcam esse movimento de periferização através de resistência dos moradores e de uma articulação política, consolidando-se como regiões administrativas mesmo sob ações violentas da Polícia Militar do DF e do Estado.

O cotidiano das pessoas que sofrem com esse processo de periferização se transformou, indicando um constante deslocamento casa-trabalho-casa. No entanto, aqui deve-se incorporar uma dinâmica casa-trabalho-hospital. Como as pessoas que vivem com HIV acessam os equipamentos? Segundo Paviani $(2011$, p.3), esse movimento pendular ocasiona elevados custos econômicos, cansaço físico e psicológico aos que se deslocam. A urbanização do DF historicamente assume um teor excludente, uma forma de urbanização que privilegia o centro e exclui a periferia, centralizando equipamentos públicos, tanto em destinação de recursos quanto à promoção de políticas públicas para saúde e educação, e que segundo Schaeffer (2003, p.238), há uma divisão estratégica do Plano Piloto em relação às RA's mais periferizadas, de em média $25 \mathrm{~km}$ para as RA's mais próximas e $40 \mathrm{~km}$ para as RA's mais distantes, instituindo uma desigualdade no acesso à saúde.

Essa agenda histórica de urbanização excludente repercute não somente nas disposições dos equipamentos públicos que são capazes de prevenir e tratar pessoas que vivem com HIV, mas sim,

\footnotetext{
${ }^{2}$ Inclui a terapia antirretroviral potente - HAART; Profilaxia Pós-Exposição ao HIV - PEP; Profilaxia PréExposição ao HIV - PrEP. 
potencializa as desigualdades pré-existentes dos grupos sociais que se encontram vulneráveis para a infecção e o adoecimento.

No DF, do início da pandemia até 2017 foram registrados 10.735 casos de HIV e AIDS (Secretaria de Saúde do DF, 2018, p.2). Já em relação aos óbitos, o DF acumula até 2016 um número expressivo de 3.573 óbitos tendo a AIDS como causa básica no Sistema de Informações sobre Mortalidade. A base de dados no DF é gerada pelo Sistema de Informação de Agravos de Notificação (SINAN) e pelo Sistema de Informação sobre Mortalidade (SIM).

O DF possui 31 regiões administrativas (RA's), sendo estas divididas em sete regiões de saúde devido às suas diferenças sociodemográficas: central, centro-sul, leste, norte, oeste, sudoeste e sul; contribuindo para a elaboração do perfil epidemiológico e a percepção das tendências ao longo dos anos. A ocupação destes territórios da cidade será caracterizada por processos complexos que ocorrem no contexto socioespacial, onde as camadas sociais habitarão setores urbanos de acordo com seu poder aquisitivo, segundo Battaus e Oliveira (2016, p.86).

Figura 1 - Tabela das Regiões de Saúde e suas respectivas RA's.

\begin{tabular}{|c|c|}
\hline $\begin{array}{c}\text { Regiões de } \\
\text { Saúde }\end{array}$ & Regiões Administrativas (RA's) \\
\hline Central & Lago Sul, Varjão do Torto, Asa Sul, Cruzeiro, Asa Norte, Sudoeste/Octogonal e Lago Norte; \\
\hline Centro-Sul & Riacho Fundo I, Núcleo Bandeirantes, Riacho Fundo II, Guará, Estrutural, Park Way, \\
& $\begin{array}{c}\text { Candangolândia e SIA; } \\
\text { Leste }\end{array}$ \\
\hline Norte & Paranoá, Jardim Botânico, São Sebastião e Itapoã; \\
\hline Oeste & Sobradinho I, Planaltina, Sobradinho II e Fercal; \\
\hline Sudoeste & Ceilândia e Brazlândia; \\
\hline Sul & Águas Claras, Taguatinga, Recanto das Emas, Samambaia e Vicente Pires; \\
\hline
\end{tabular}

Fonte dos dados: BE de HIV/AIDS da SES - DF (2018). Produção própria.

Desse modo, considerando o fenômeno de HIV e AIDS no Distrito Federal questiona-se: Como os serviços e equipamentos públicos de prevenção e tratamento estão sendo utilizados? Em que região do DF estão localizadas? Quem são os usuários? E por fim, quais conflitos emergem do uso desigual da cidade, do território e dos equipamentos públicos?

Esta pesquisa tem por objetivo geral compreender o cenário epidemiológico do HIV e da AIDS no DF, de modo a diferenciar a espacialidade das infecções (HIV) e a espacialidade dos adoecimentos (AIDS). Desta maneira, de forma específica, objetiva-se a) Espacializar os dados do BE da Secretaria de Saúde - DF no período de 2012 a 2017, através do software de georreferenciamento gratuito QGIS; b) Classificar as principais Regiões Administrativas com um perfil epidemiológico que 
necessita de políticas públicas específicas; c) Apresentar produções cartográficas que contribuam com o monitoramento dos casos de HIV e AIDS, auxiliando o delineamento das ações preventivas e de resposta à pandemia.

\section{PERCURSOS METODOLÓGICOS}

Realizou-se inicialmente uma pesquisa documental e descritiva do boletim epidemiológico de HIV e AIDS do DF, publicado pela Secretaria de Saúde do DF (SES-DF) através da Subsecretaria de Vigilância à Saúde (http://www.saude.df.gov.br/dst-aids/). Estes dados estão relacionados à base de dados do Sistema de Informações de Agravos de Notificação (SINAN), bem como ao Sistema de Informações sobre Mortalidade (SIM), e por fim, ao Instituto Brasileiro de Geografia e Estatística (IBGE).

O boletim foi publicado em 2018, contudo, sob recorte temporal dos anos de 2012 a 2017. O objetivo foi coletar dados secundários e realizar uma análise espacial da incidência do HIV e da AIDS mediante abordagem da Geografia da Saúde, uma vez que "a geografia da saúde procura compreender o contexto em que ocorrem os problemas de saúde, para poder atuar sobre os territórios" (Barcellos; Buzai; Handschumacher; 2018, p.17). A intenção é evidenciar as RA's com os maiores coeficientes de incidência do HIV e AIDS por meio de técnicas de georreferenciamento destes dados, traçando um cenário epidemiológico através do software QGIS versão 3.14.0.

As ferramentas de georreferenciamento utilizadas na pesquisa são um conjunto de tecnologias manuseadas para a realização da coleta de dados, o processamento e o diagnóstico (Rosa e Brito, 1996). Refere-se às etapas da análise espacial e auxilia em um processo de tomadas de decisões mais assertivas. Estas informações geográficas são consideradas um conjunto de dados físicos e sociais, com seus significados associados diretamente a uma localidade específica, e neste caso, situado no tempo e no espaço de forma singular, pois, a pandemia de HIV e AIDS está presente na cidade, no espaço urbano, tendo seu epicentro em regiões de saúde específicas.

O coeficiente de incidência representa o números de casos de HIV e AIDS em um determinado ano de diagnóstico e local de residência, dividido pela população de residentes nesse mesmo local e ano de notificação, multiplicado por 100.000 (BE de HIV/AIDS, Brasil, 2019, p. 69), conforme fórmula abaixo. Compreende-se I) "n" como número de casos novos de HIV ou AIDS em um determinado ano de diagnóstico e local de residência; II) "p" como população de residentes nesse mesmo local, no mesmo ano de notificação; III) "ci" como coeficiente de incidência. A utilidade desse dado se dá na mensuração do risco de ocorrência de novos casos confirmados de HIV e AIDS na população.

Figura 2 - Fórmula do coeficiente de incidência utilizado para georreferenciamento.

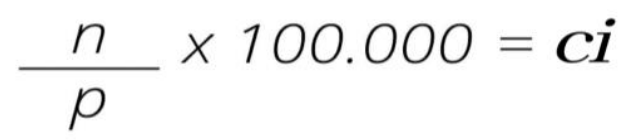

Fonte dos dados: BE de HIV/AIDS do Brasil (2019). Produção própria.

Os dados do coeficiente de incidência de HIV e AIDS foram categorizados na tabela de atributos do shapefile do DF, a partir do censo de 2010, obtido na plataforma "GEOPORTAL DF" (https://www.geoportal.seduh.df.gov.br/mapa/\#), acrescentados manualmente para uma classificação gradiente em diversas tonalidades de vermelho. O método permite visualizar as RA's com maiores incidências quando georreferenciado, portanto, cria-se um cenário de inferências sobre a espacialidade do fenômeno. O vermelho utilizado faz parte de uma escolha metodológica, pois a cor representa um imaginário social. Busca-se alcançar um aspecto lúdico deste processo de ensinoaprendizagem em relação à pandemia de HIV e AIDS.

De forma técnica, elaborou-se um arquivo no excel contendo diversas informações para cruzamento, a fim de subsidiar uma análise do cenário epidemiológico. A primeira parte desse aglomerado de informações consiste em: a) Nome da Região Administrativa; b) População total; c) Índice de Gini das RA's no ano de 2018; Índice de Desenvolvimento Humano Municipal (IDHM) no ano de 2010; Classe 
social, e por fim, informações quanto ao perfil étnico racial da população por RA, segundo a Pesquisa Distrital por Amostras de Domicílios - PDAD 2018.

A segunda parte consiste em informações acerca do HIV, com o intuito de diferenciar os fenômenos de infecção e adoecimento, consistindo em: a) Nome da Região Administrativa; b) Coeficiente de incidência separado por ano, de 2012 a 2017; c) Tendência, indicando se houve crescimento, decrescimento ou variação; d) Cálculo da Média do período; e) Status da Média, indicando ser alta, média, ou baixa ; f) Cálculo da diferença entre o último ano e o primeiro, sendo 2017 - 2012, a fim de observar quantitativamente as tendências; g) Análise da diferença, apresentando aumento ou redução; h) Hotspots, apontando as RA's que se destacam e por fim; i) Observação, a fim de evidenciar alguma análise relevante.

Figura 3 - Tabela do Excel utilizada para tabulação dos dados.

\begin{tabular}{|c|c|c|c|c|c|c|c|c|c|}
\hline$\Delta$ & A & B & c & D & E & $\mathrm{F}$ & G & & $\mathrm{H}$ \\
\hline 1 & Região Administrativa & CD 2012 & CD 2013 & CD 2014 & CD 2015 & CD 2016 & CD 2017 & & Tendências \\
\hline 2 & Lago Sul & 36,3 & 27,6 & 32,6 & 23 & 19,5 & & 11,2 & Tendência de Decrescimento com intervalo. \\
\hline 10 & Varjăo do Torto & 0 & 0 & 9,8 & 0 & 9,5 & & 0 & Região Administrativa não apresenta população relevante. Abaixo de 10.000 . \\
\hline 12 & Santa Maria & 12,3 & 14,9 & 19,2 & 16,6 & 8,1 & & 13,6 & Tendência de variação de cresc/decrescimento do coeficiente. \\
\hline 13 & Planaltina & 12,5 & 11,3 & 11,6 & 18,7 & 15,3 & & 14 & Tendência de variação de cresc/decrescimento do coeficiente. \\
\hline 20 & Guará & 23,7 & 27,4 & 36,7 & 37,4 & 34,1 & & 32,1 & Tendência de Crescimento com Intervalo. \\
\hline 31 & São Sebastião & 3,4 & 6,5 & 21,4 & 21,1 & 28 & & 27,6 & Tendência de Crescimento em todo o período. \\
\hline 32 & Riacho Fundo I & 16,2 & 28,3 & 7,5 & 24,6 & 31,3 & & 41,7 & Tendência de Crescimento com Intervalo. \\
\hline
\end{tabular}

Fonte dos dados: BE de HIV/AIDS da SES - DF (2018). Produção própria.

A terceira parte consiste em outro aglomerado de informações, desta vez com foco no fenômeno da AIDS, portanto, somente dados de pessoas que no momento do diagnóstico apresentavam um quadro de imunodepressão avançada. A tabela segue o mesmo formato da citada anteriormente. Foram definidos parâmetros para os dados de HIV e AIDS, uma vez que os coeficientes seguem tendências diferenciadas. Segue abaixo as especificações de HIV e AIDS:

1. Tendências HIV: I) Crescimento em todo o período; II) Crescimento com Intervalo; III) Variação de crescimento e decrescimento do coeficiente; IV) Decrescimento com Intervalo; V) Região Administrativa não apresenta população relevante. Abaixo de 10 mil habitantes.

2. Médias HIV: I) De 0 a 10 = Baixa; II) De 10,1 a 17,9 = Média; III) De 18 a 25 = Alta; IV) De 25 em diante = Muito Alta; V) Irrelevante.

3. Cálculo da Diferença HIV: I) De 0 a 9,9= Aumento Tênue; II) De 10 em diante = Aumento Evidente; III) De -5 a 0 = Redução Tênue; IV) De -30 a -6 = Redução Evidente; V) Irrelevante.

4. Tendências AIDS: I) Decrescimento em todo o período; II) Decrescimento com Intervalo; III) Decrescimento com Estabilidade; IV) Variação de crescimento e decrescimento do coeficiente; V) Crescimento com Intervalo; VI) Região Administrativa não apresenta população relevante. Abaixo de 10 mil habitantes.

5. Médias AIDS: I) De 0 a 10,8 = Baixa; II) De 10,9 a 17,9 = Média; III) De 18 a 25 = Alta; IV) De 25 em diante = Muito Alta; $\mathrm{V}$ ) Irrelevante.

6. Cálculo da Diferença AIDS: I) De 0 a 2,9 = Aumento Tênue; II) De 3 em diante = Aumento Evidente; III) De -5 a 0 = Redução Tênue; IV) De -30 a -6 = Redução Evidente; V) Irrelevante.

Posteriormente foram elaborados gráficos das principais RA's que se configuram como Hot Spots de HIV e AIDS. Por fim, elaborou-se tabelas diferenciadas das Regiões de Saúde para cada fenômeno, a fim de espacializar a análise por grupos. Houve um tratamento dos dados para evidenciar quais RA's dentro das regiões de saúde se destacam.

Compreendendo que o coeficiente de incidência é um cálculo altamente influenciado pelo total da população, as RA's do Varjão do Torto, SIA e Fercal não foram consideradas, uma vez que todas apresentam uma população abaixo de 10 mil habitantes. Nesta pesquisa foram consideradas apenas RA's acima desse limiar. 


\section{RESULTADOS E DISCUSSÃO}

\section{Espacialidade do HIV}

Uma vez que os mapas da distribuição espacial do HIV e da AIDS no DF foram elaborados, tornou-se possível visualizar um cenário epidemiológico a partir de um olhar que formule políticas públicas voltadas para as RA's com maior incidência do vírus e da doença. O mapa a seguir apresenta a espacialidade do HIV de acordo com o recorte temporal determinado neste estudo, utilizando o cálculo da média dos coeficientes de incidência com o objetivo de padronizar os dados. Quanto mais escuro ou intenso for o vermelho, maior será a média do coeficiente de incidência de HIV, sendo o contrário proporcional.

Figura 5 - Mapa da espacialidade do HIV, baseado na média dos coeficientes de incidência no período analisado.

\section{MAPA DA ESPACIALIDADE DO HIV NO DISTRITO FEDERAL CENÁRIO EPIDEMIOLÓGICO DE 2012 A 2017}

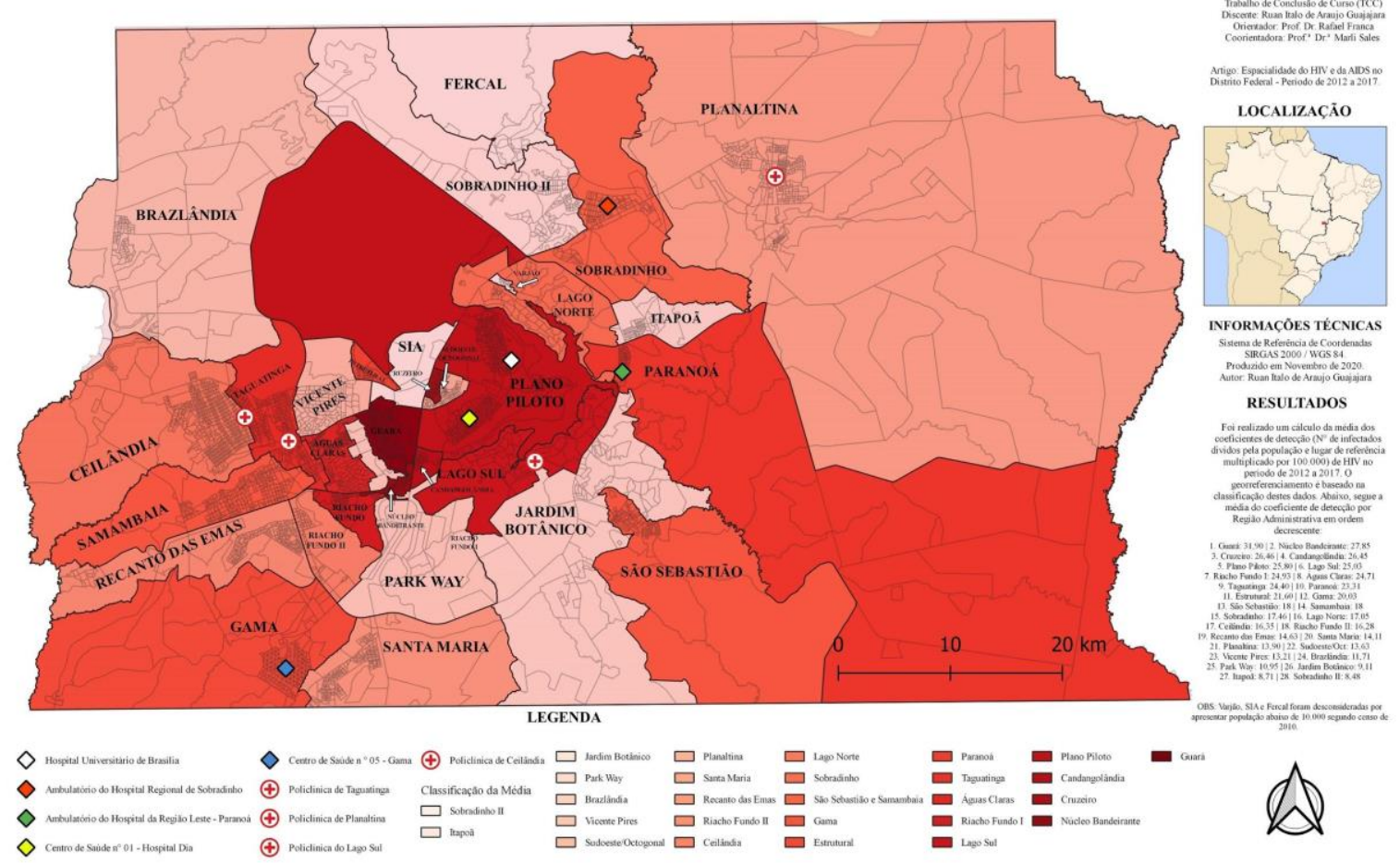

Fonte dos dados: BE de HIVIAIDS da SES - DF (2018). Produção própria.

No período analisado foram diagnosticados 3.352 novos casos de HIV, onde a razão entre os sexos masculino e feminino (M:F) se encontra na média de 5,4 homens para cada mulher. Neste período de notificação, percebe-se uma proporção maior em homens do que em mulheres, apresentando uma tendência de crescimento e demonstrando maior vulnerabilidade dos homens em relação à infecção pelo HIV.

As regiões administrativas que apresentaram maior coeficiente de incidência em relação ao total de casos de HIV no período analisado, foram: Riacho Fundo I, Núcleo Bandeirante, Candangolândia, Guará, Águas Claras e Taguatinga. Nota-se uma centralização dessa incidência em duas regiões de saúde, onde as quatro primeiras RA's são oriundas da região de saúde centro sul e as demais da região de saúde sudoeste.

De acordo com Santos (1988), a espacialidade é um momento das relações sociais geografizadas, ou seja, o momento da incidência da sociedade sobre um determinado arranjo espacial. O fenômeno da espacialidade do HIV concentrado em regiões de saúde específicas, estando conurbadas em alguns 
lugares, indica uma reprodução crescente da pandemia em regiões que apresentam indicadores sociodemográficos semelhantes, como renda, mobilidade, acesso aos serviços e equipamentos, e por fim, um potencial de interação urbana, aplicando um modelo de gravidade nas relações sociais (NOSSA, 2018, p. 41). Quanto maior e mais complexo for o grau de mobilidade ${ }^{3}$ maior será a probabilidade de interação entre os indivíduos entre centros urbanos hierarquicamente diferenciados. A probabilidade do processo de infecção se desloca hierarquicamente entre áreas com elevado potencial de interação, originando epicentros regionais de contágio.

Percebe-se a possibilidade da existência de um epicentro das infecções. Esta centralidade vem se mantendo a mesma ao longo dos anos, mesmo com uma variação do crescimento e decrescimento do coeficiente. A utilização de ferramentas de georreferenciamento, seguindo um pensamento que considere o território a partir de seu uso, possibilita que políticas públicas assertivas sejam desenvolvidas para as duas regiões de saúde que apresentam dados axiomáticos.

As regiões administrativas que obtiveram maior tendência de aumento do coeficiente de incidência do HIV foram Guará e Núcleo Bandeirante, apresentando as maiores médias do período, sendo 31,9 e 27,85 respectivamente, ambas classificadas como muito alto. Seguido por Candangolândia $(26,45)$, Plano Piloto $(25,8)$ e Riacho Fundo I $(24,93)$. Vale destacar São Sebastião, pois a RA apresenta um dos maiores aumentos comparando os anos, saltando de 3,4 em 2012 para 27,6 em 2017, classificada como um aumento evidente. De forma geral, a maioria das regiões administrativas segue a tendência de aumento dos casos de HIV. Abaixo, selecionou-se algumas RA's que se destacaram.

Figura 6 - Gráfico das RA's que apresentaram maior aumento do coeficiente de incidência por HIV.

\section{Regiões Administrativas que obtiveram maior aument o do Coeficiente de Incidência por HIV}

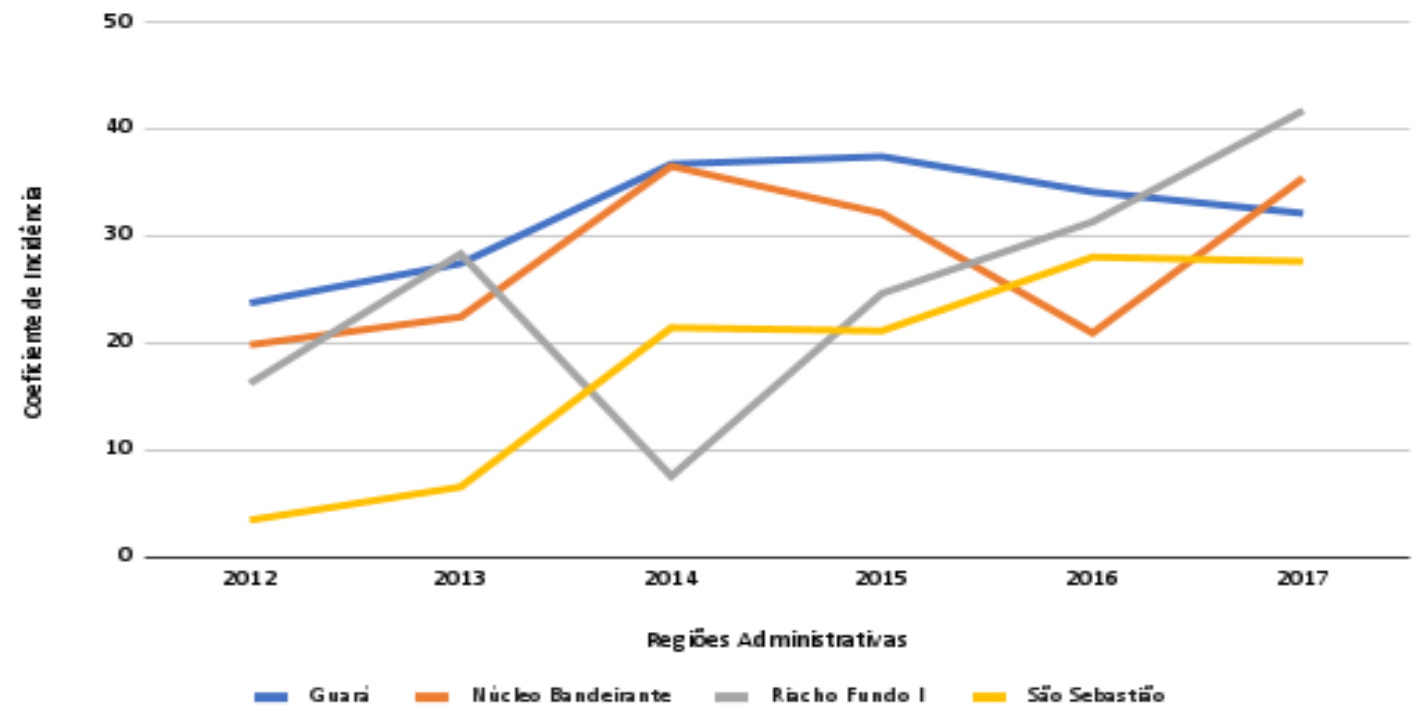

Fonte dos dados: BE de HIV/AIDS da SES - DF (2018). Produção própria.

No que diz respeito ao perfil étnico racial da população dessas RA's, nota-se que a população negra ${ }^{4}$ se destaca em três regiões, sendo São Sebastião (64\%), Riacho Fundo (58\%) e Núcleo Bandeirante (53\%), dialogando com um perfil de maior vulnerabilidade. Guará apresenta $52 \%$ de sua população como branca e $46 \%$ como negra. Quanto à renda domiciliar per capita $(\mathrm{R} \$)$, nota-se que Guará e Núcleo Bandeirante apresentam as maiores rendas, com $R \$ 3.368,76$ e $R \$ 2.365,57$ respectivamente. Já Riacho Fundo I e São Sebastião apresentam R\$1.328,16 e R\$1.051,43. Essas RA's destacam-se

\footnotetext{
${ }^{3}$ Ônibus, metrô, trem, carros, meios de transporte alternativo ou qualquer tipo de transporte disponível, somando ao potencial de relações econômicas, políticas e culturais no lugar de referência.

${ }^{4}$ Pretos e pardos segundo a Pesquisa Distrital por Amostra de Domicílios - PDAD, 2018.
} 
pois a renda domiciliar per capita se aproximam ao salário mínimo, indicando ser regiões administrativas potencialmente mais periferizadas e empobrecidas.

Quando se considera o Índice de Gini (2018), as RA's em análise variam de 0.43 (São Sebastião) a 0.53 (Núcleo Bandeirante), indicando uma média concentração de renda. Já em relação ao IDHM (2010), que aponta uma medida de indicadores do desenvolvimento humano, avaliando longevidade, educação e renda, Guará e Núcleo Bandeirante destacam-se apresentando os maiores indicadores, com 0.897 e 0.888 respectivamente, apontando um cenário de amplo desenvolvimento. Riacho Fundo I e São Sebastião apresentam valores inferiores, respectivamente, 0.797 e 0.761 , sendo um dos menores IDHM do DF, contudo, apresenta indicador satisfatório quando comparado à grande maioria dos municípios brasileiros. O IDHM (2010) não evidencia um contraste evidente entre as RA's, contudo, ao cruzar esse índice com elementos como renda domiciliar per capita, torna-se possível visualizar pequenos contrastes no perfil das RA's que apresentaram maiores coeficientes de incidência por HIV.

O fenômeno de infecção por HIV é complexo, demandando a utilização de diversos indicadores para a reflexão do porquê a alta incidência nessas regiões, uma vez que é observado em RA's mais desenvolvidas e em menos desenvolvidas. Todas apresentam um grau de complexificação da interação urbana, sugerindo um aumento na possibilidade de contágio nas suas populações.

Em relação a uma maior redução do coeficiente de incidência do HIV, destacam-se as RA's do Lago Sul e Park Way, contudo, ambas apresentam médias altas. No entanto, é possível verificar uma tendência de diminuição das infecções. As demais RA's que apresentaram diminuição do cálculo também verificam tendências de variação, o que dificulta uma análise assertiva quanto à diminuição.

Figura 7 - Gráfico das RA's que apresentaram maior redução do coeficiente de incidência por HIV.

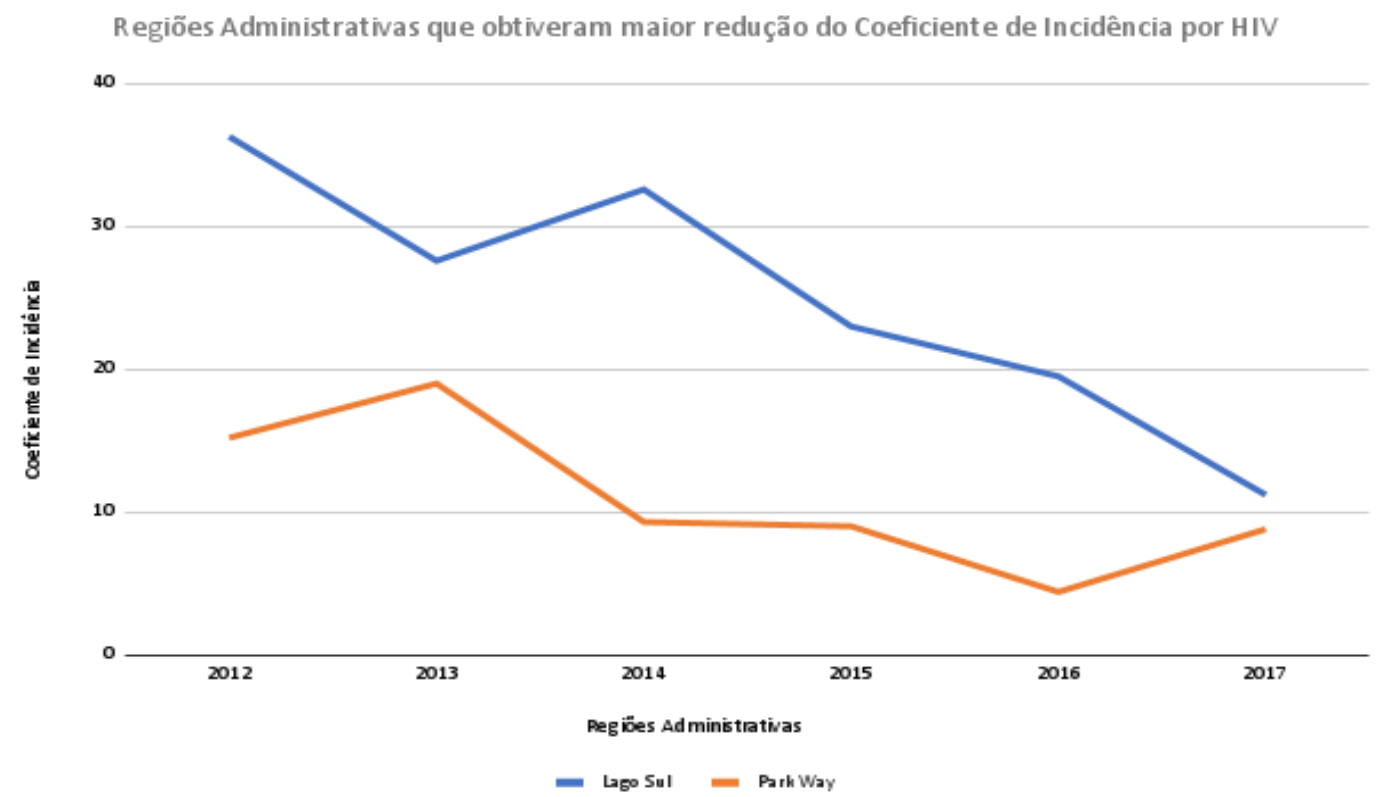

Fonte dos dados: BE de HIV/AIDS da SES - DF (2018). Produção própria.

Comparando o perfil étnico racial das RA's que apresentaram diminuição, observa-se que o Lago Sul tem uma população majoritariamente branca, expressando $76 \%$ do total, enquanto Park Way indica $68 \%$ da população como branca. Quanto à renda domiciliar per capita, nota-se que ambas apresentam as maiores rendas do DF, sendo $\mathrm{R} \$ 8.355,04$ para o Lago Sul e $\mathrm{R} \$ 6.138,45$ para o Park Way. No que se refere ao índice de Gini (2018), Lago sul apresenta 0.39 e Park Way 0.49, indicando uma alta concentração de renda. Já no tocante ao IDHM (2010), Lago Sul indica ter 0,955, o mais alto índice registrado no DF, e Park Way com 0.888. Aponta-se maior contexto de desenvolvimento humano nessas regiões administrativas, sugerindo-se, a partir de uma análise transversal, a 
diminuição no coeficiente de incidência por HIV em regiões com o IDHM alto, podendo ou não haver uma correlação entre os dois fenômenos. Abaixo, segue o mapa da série histórica da espacialidade do HIV, com intuito de visualizar espacialmente as tendências.

Figura 8 - Mapa da série histórica do HIV.

\section{MAPA DA SÉRIE HISTÓRICA DE HIV NO DISTRITO FEDERAL CENÁRIO EPIDEMIOLÓGICO DE 2012 A 2017}

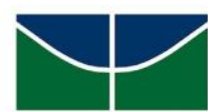

2012

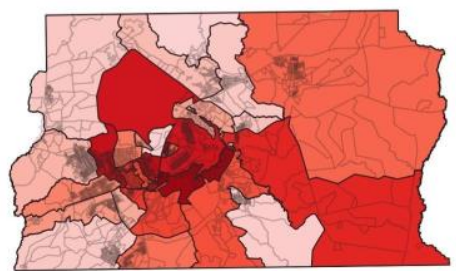

2015

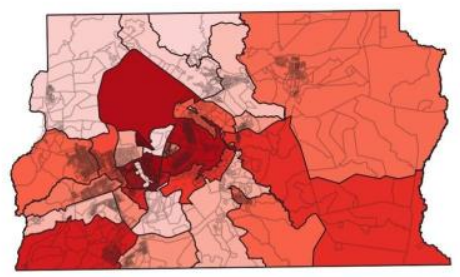

INFORMAÇÕES TÉCNICAS
2013

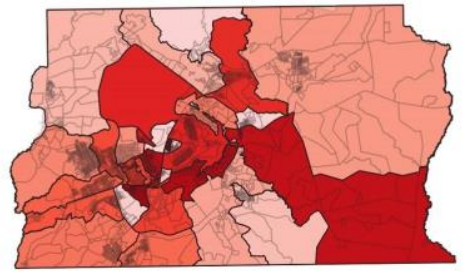

2016

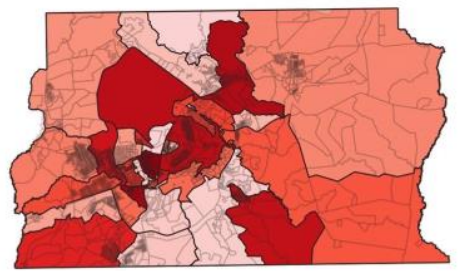

LOCALIZAÇ̃̃o

Sistema de Referência de Coordenadas Universidade de Brasilia - UnB SIRGAS 2000 / WGS $84 . \quad$ Departamento de Geografia - GEA/UnB Produzido em Novembro de 2020 Por: Ruan Italo de Araujo Guajajara Artigo: Espacialidade do HIV e da AIDS no Orientador: Prof. Dr. Rafael Franca
Distrito Federal - Periodo de 2012 a 2017 . Coorientadora: Prof." Dr." Marli Sale Trabalho de Conclusão de Curso (TCC) Discente: Ruan Italo de Araujo Guajaj Coorientadora: Prof. ${ }^{a}$ Dr.a Marli Sales

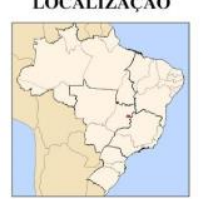

2014

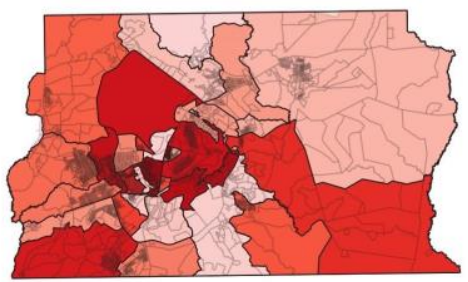

2017

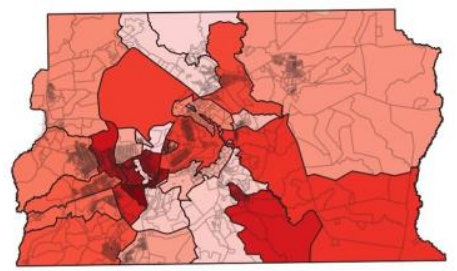

RESULTADOS

O georreferenciamento é baseado na classificação dos dados do coeficiente de deteç̧âo de HIV por Região Administrativa en ordem decrescente. Percebe-se que há um epicentro das infecçồ nas regiōes de Saúde Centro Sul (destacando CandangolândiGuará, Nucleo Bandeirante e Rlacho Fundo I e II) e Centr (destacando Plano um crescimento exponencial nas regiōes de saúde
(destacando Taguatinga e Águas Claras) e Leste (Paranoá).

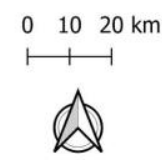

$0 \quad 1020 \mathrm{~km}$

Fonte dos dados: BE de HIV/AIDS da SES - DF (2018). Produção própria.

Com respeito às tendências anuais verificadas, observa-se que há uma permanência do epicentro de infecções, destacando a área central do DF em um tom avermelhado mais escuro, desde 2012 a 2017. Contudo, no último ano analisado, percebe-se que o Plano Piloto ${ }^{5}$ perde protagonismo nas infecções, cedendo espaço para a região de saúde centro-sul e sudoeste, que apresentam-se como regiões de alta incidência desde 2012. Durante o período, é possível identificar que as regiões do Lago Sul e Park Way vão perdendo intensidade de cor, chegando em 2017 com um tom esbranquiçado, indicando coeficiente de incidência por HIV baixo.

Percebe-se também ao longo das tendências anuais, uma participação eventual de regiões administrativas periferizadas, como Gama, localizado na região de saúde sul, e Paranoá, localizado na região de saúde Leste, reforçando uma atenção futura nesta região de saúde, uma vez que São Sebastião também apresenta protagonismo nas infecções. Ambas regiões administrativas apresentam uma população em maioria negra, com 65\% (Gama) e 67\% (Paranoá). Cabe ressaltar também a participação da região administrativa de Águas Claras, constituindo-se como uma região de classe média, apresentando $59 \%$ de sua população como branca. Portanto, compreende-se que há uma possibilidade do fenômeno de aumento das infecções por HIV estar parcialmente concentrado em regiões de classe média e classe média baixa no DF, enquanto as regiões que apresentam maior redução se configuram como região de classe média alta ou alta.

\footnotetext{
${ }^{5}$ Pertencente à região de saúde central.
} 
Em relação à transmissão vertical do HIV, que ocorre na passagem do vírus da mãe para o filho durante a gestação, parto, ou amamentação, as RA's que apresentam maiores incidências são a Estrutural, Paranoá, Sobradinho I e Taguatinga. Caracteriza-se a transmissão vertical como um dos principais indicadores do sucesso do tratamento, pois, se há um pré-natal eficiente, não seria possível uma transmissão do vírus. Acentuam-se os dados da Estrutural, uma vez que esta RA se configura como uma das regiões mais empobrecidas do DF, em um contexto de favelas, antigos lixões e situações de moradias precarizadas, o que influencia no tratamento e na chegada dos equipamentos públicos que seriam capazes de atender tais demandas. Pode indicar um cenário de falha na política de prevenção e tratamento nessa RA.

\section{Espacialidade da AIDS}

No período analisado, a razão entre sexos masculino e feminino (M:F) em relação a AIDS encontrase na média de 4,1 homens para cada mulher, indicando maior participação masculina, contudo, cabe evidenciar também um cenário de maior participação feminina em um contexto de adoecimento, dialogando com aquilo que Brito et al aponta ser uma heterossexualização e feminização da doença (2000, p.210). No total de casos de AIDS acumulados no período, as regiões administrativas com maiores coeficientes de incidência foram: Riacho Fundo I, Águas Claras, Taguatinga, Paranoá, Sobradinho I e Núcleo Bandeirante. Diferentemente do processo de infecção por HIV, no processo de adoecimento por AIDS surgem novas regiões de saúde protagonistas, como a região de saúde Leste (Paranoá) e Norte (Sobradinho I), indicando maior espacialização da doença nas bordas do DF, afastando-se da região central. Contudo, ainda percebe-se um epicentro nas regiões de saúde centro sul e sudoeste.

Figura 9 - Mapa da espacialidade da AIDS, baseado na média dos coeficientes de incidência no período analisado.

\section{MAPA DA ESPACIALIDADE DA AIDS NO DISTRITO FEDERAL CENÁRIO EPIDEMIOLÓGICO DE 2012 A 2017}

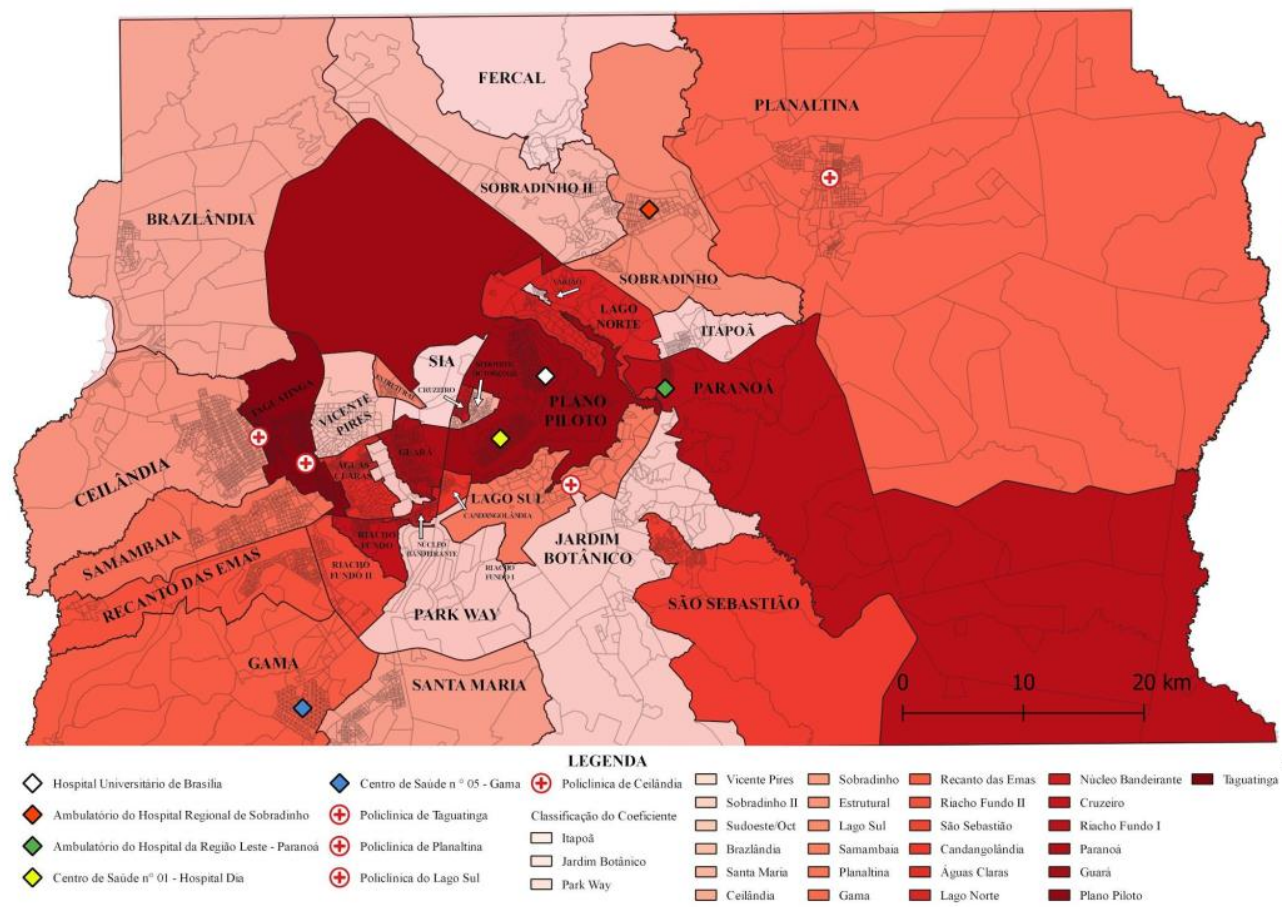

Fonte dos dados: BE de HIV/AIDS da SES - DF (2018). Produção própria.
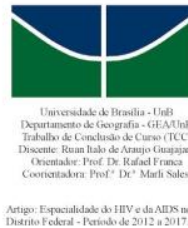

LOCALZACÃo

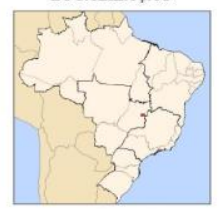

INFORMAC̄õES TÉCNICAS

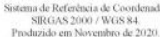
RESULTADOS

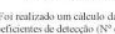
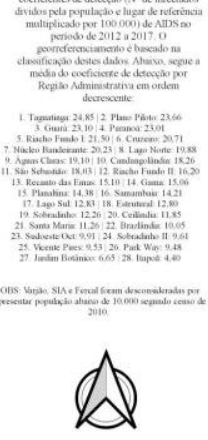

Analisando o mapa das médias de HIV e AIDS percebe-se que há uma padronização dos coeficientes, onde não se verifica uma diferença evidente entre o mapa de média de HIV e o mapa da 
média de AIDS. Contudo, observa-se maior intensidade do vermelho na região administrativa do Paranoá, evidenciando que diferentemente do processo de infecção, nesta região o processo de adoecimento foi mais intenso.

Segundo a Secretaria de Saúde do GDF existem nove unidades públicas de saúde que possuem ambulatórios especializados na prevenção e no cuidado às pessoas que vivem com HIV, bem como o tratamento das pessoas que desenvolveram AIDS, tornando necessário o georreferenciamento desses equipamentos, como policlínicas e hospitais, mapeados como pontos no mapa acima. Postos de saúde não foram contabilizados, uma vez que o serviço prestado se dá no campo Atenção Básica, como ações de prevenção, testes, consultas e encaminhamentos.

Os serviços específicos de tratamento da AIDS ocorrem em equipamentos públicos especializados, localizados em: a) Policlínica de Planaltina; b) Ambulatório do Hospital Regional de Sobradinho; c) Policlínica de Ceilândia; d) Centro de Saúde no 5 do Gama; e) Hospital Universitário de Brasília - UnB; f) Hospital Dia da Asa Sul; g) Policlínica de Taguatinga; h) Ambulatório de HIV/AIDS do HRL (Hospital da Região Leste - Paranoá); i) Policlínica do Lago Sul. Todavia, verifica-se que atualmente os serviços de acompanhamento e tratamento aos novos diagnosticados com HIV e AIDS no DF ocorrem somente na região central, nas unidades do Hospital Dia e do Hospital Universitário de Brasília - HuB. Aqui, verifica-se a necessidade futura de aplicações de questionário para investigar de fato onde tem sido tratado a AIDS.

Contrariando uma tendência regional e nacional de redução dos casos de AIDS, as regiões administrativas que apresentaram maior aumento do coeficiente de incidência foram Riacho Fundo I e Sobradinho I. Riacho Fundo I apresenta uma tendência de crescimento com intervalo, exibindo uma média alta de casos, em 21,5. Verifica-se um aumento tênue, com coeficiente de incidência de AIDS em 21,7 no ano de 2012, para 22,1 no ano de 2017. Já a região administrativa de Sobradinho I também apresenta uma tendência de crescimento com intervalo, exibindo uma média dos coeficientes de incidência em 12,26, classificada como intermediário. Contudo, observa-se um aumento evidente do coeficiente, saltando de 12,7 em 2012 para 15,8 em 2017.

É possível que essas regiões administrativas estejam em um período de estabilidade. Através de uma análise multiescalar seria possível confirmar tal hipótese, contudo, como a série histórica apresenta uma fragilidade quanto aos anos analisados, não foi possível identificar tal estabilidade, indicando apenas um tênue aumento do coeficiente de incidência por AIDS. No entanto, a maioria das regiões administrativas reduziram seu coeficiente, enquanto Riacho Fundo I e Sobradinho I aumentaram. Tal aumento demonstra atenção nessas regiões em um contexto de diminuição geral.

Figura 10 - Gráfico das RA's que apresentaram maior aumento do coeficiente de incidência por AIDS.

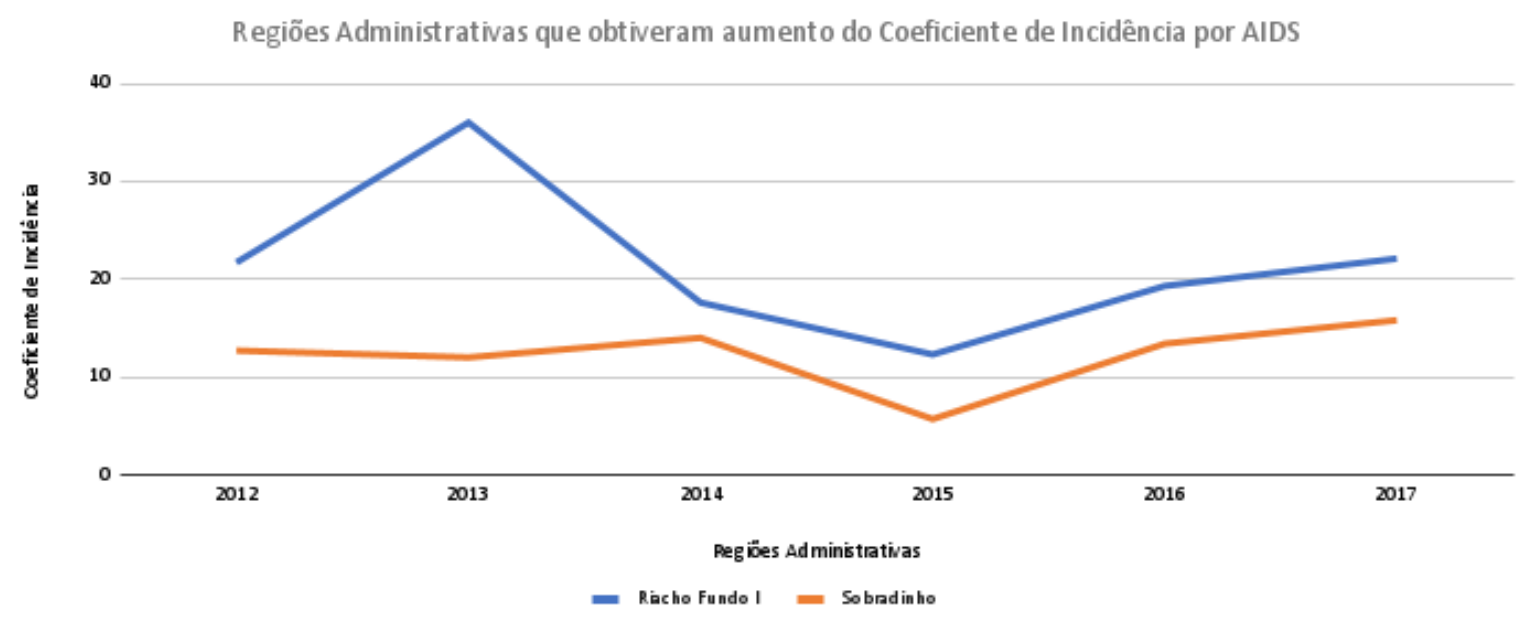

Fonte dos dados: BE de HIV/AIDS da SES - DF (2018). Produção própria.

Como as informações relacionadas ao perfil das pessoas que vivem na região administrativa do Riacho Fundo I já foram mencionadas, aqui serão abordadas somente as relacionadas à região 
administrativa de Sobradinho I. No que diz respeito ao perfil étnico racial, Sobradinho I apresenta uma população em maioria negra, com $55 \%$ do total. Sua renda domiciliar per capita é definida em $\mathrm{R} \$ 2.516,79$, constituindo-se como uma região de classe média, apresentando também um índice de Gini (2018) em 0.49, indicando uma média concentração de renda. Quanto ao IDHM (2010), o índice de 0.801 se apresenta como alto. Contudo, ainda revela um contraste com regiões como o Lago Sul, que apresenta o maior indicador em 0.955.

Analisando o coeficiente de incidência do perfil étnico racial em relação à AIDS, observa-se maioria entre negros, sendo $51,4 \%$ em homens e $58,9 \%$ em mulheres. Quanto à categoria de exposição, nota-se que $84,6 \%$ dos casos em mulheres ocorreram em relações heterossexuais, em contrapartida, observa-se que $64,2 \%$ dos casos em homens ocorreram a partir de relações homossexuais, contabilizando gays e bissexuais. No entanto, ainda em relação aos homens, ressalta-se a participação de heterossexuais, com $23,7 \%$ dos casos. Compreende-se também que há uma parcela subnotificada de homens que fazem sexo com homens $(\mathrm{HSH})$ nesse cálculo.

Já em relação à faixa etária das pessoas que desenvolveram AIDS, verifica-se que em ambos os sexos há uma predominância da fase adulta, entre 20 a 39 anos, correspondendo $62,7 \%$ dos casos. Ressalta-se a importância de políticas públicas voltadas para a juventude, compreendida entre 15 a 29 anos, correspondendo a $30 \%$ dos casos totais no período analisado.

O indicador do grau de escolaridade, utilizado para uma análise indireta do nível social, evidencia que cerca de $32,6 \%$ dos homens que desenvolveram AIDS ${ }^{6}$ possuem grau de escolaridade avançado, composto por ensino superior em andamento $(11,4 \%)$ e ensino superior completo $(21,2 \%)$, dialogando com a renda per capita alta das regiões de saúde que apresentaram maiores incidências, sendo a centro sul e sudoeste, classificando-as como RA's de classe média. Já em relação às mulheres, nota-se um grau de escolaridade menor, destacando ensino fundamental incompleto com $24,6 \%$. Aqui, vale ressaltar o perfil das mulheres que têm desenvolvido AIDS, sendo mulheres heterossexuais, negras, jovens e com tendência a uma baixa escolaridade.

Com relação aos óbitos, de 1985 a 2016, foram contabilizados 3.573 óbitos, indicando que mesmo após avanços imensuráveis, ainda há mortes no DF tendo a AIDS como causa básica. Contudo, percebe-se uma tendência de diminuição, saltando de 126 óbitos em 2012 para 105 em 2017, estabelecendo um número total de 709 mortes no período analisado, sendo 513 em homens e 196 em mulheres.

Figura 11 - Gráfico das RA's que apresentaram maior redução do coeficiente de incidência por AIDS

Regiões Administrativas que obtiveram maior redução do Coeficiente de Incidência por AIDS

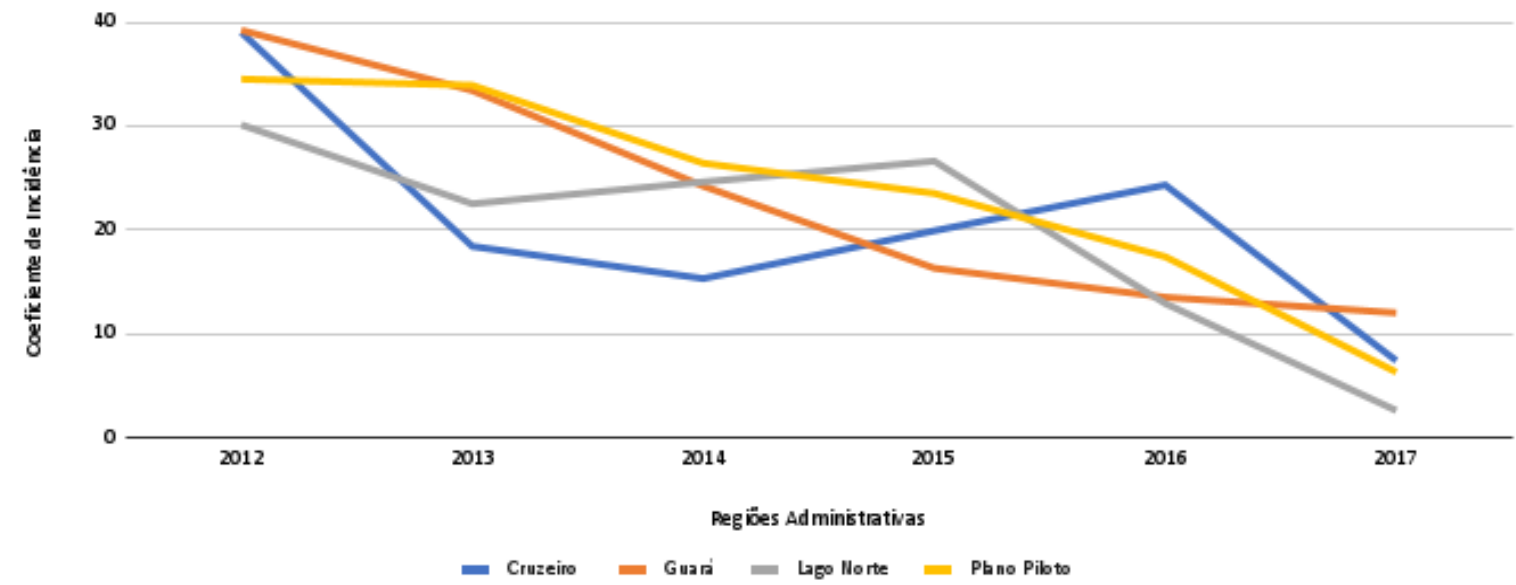

Fonte dos dados: BE de HIV/AIDS da SES - DF (2018). Produção própria.

\footnotetext{
${ }^{6} \mathrm{O}$ boletim epidemiológico não apresenta informações quanto ao perfil em casos de HIV, somente AIDS, apresentando: a) grau de escolaridade; b) Faixa etária; c) Perfil étnico racial; d) Exposição. 
No que concerne a uma maior redução do coeficiente de incidência da AIDS, destacam-se as RA's do Cruzeiro, Lago Norte, Plano Piloto e Guará. As três primeiras apresentam tendências de decrescimento com intervalo, enquanto Guará apresenta uma tendência de decrescimento em todo o período, saltando de 39,2 em 2012 para 12 em 2017, uma alteração em -27,2, classificada como uma redução evidente. Ao mesmo tempo que esta região administrativa se classifica por um grande aumento do coeficiente de HIV, ela também se destaca por uma alta redução do coeficiente por AIDS. A RA do Cruzeiro saltou de $39 \mathrm{em} 2012$ para 7,4 em 2017, enquanto que o coeficiente do Plano Piloto salta de 34,5 em 2012 para 6,3 em 2017. O Lago Norte também chama atenção, alterando de 39,2 em 2012 para 2,6 em 2017, aproximando-se de um coeficiente de incidência por AIDS ideal.

Vale comentar sobre a região administrativa de Taguatinga, que apresenta a maior média do coeficiente de AIDS $(24,85)$ em todo o período, contudo, também apresenta uma das maiores tendências de redução do coeficiente. Demais regiões administrativas também se encaixam na tendência geral de diminuição da AIDS.

Em relação ao perfil das RA's que apresentaram maior redução do coeficiente da AIDS, observa-se que a renda domiciliar per capita é alta, variando de seis mil reais (Lago Norte e Plano Piloto) a três mil reais (Cruzeiro). De forma geral, todas apresentam um IDHM (2010) alto, acima de 0.900, indicando um processo de desenvolvimento humano acentuado. Contudo, em relação ao índice de Gini (2018), observa-se uma diferença, Lago Norte e Plano apresentam 0.47 e 0.46 respectivamente, e Cruzeiro apresenta 0.38 , indicando maior concentração de renda. No que se refere ao perfil étnico racial dessas RA's, Lago Norte e Plano Piloto apresentam ambas $64 \%$ de sua população como branca, enquanto Cruzeiro apresenta $51 \%$ de negros e $49 \%$ de brancos. Percebe-se que há uma tendência de diminuição dos casos de AIDS em regiões administrativas de classe média alta e alta, sugerindo menor vulnerabilidade dessas populações quanto ao processo de adoecimento por AIDS.

É possível indicar que há um aumento dos casos de infecção por HIV em regiões administrativas de classe média e classe média baixa, enquanto há uma maior redução dos casos de AIDS em regiões administrativas de classe média alta e alta.

Figura 12 - Mapa da série histórica da AIDS.

\section{MAPA DA SÉRIE HISTÓRICA DE AIDS NO DISTRITO FEDERAL CENÁRIO EPIDEMIOLÓGICO DE 2012 A 2017}

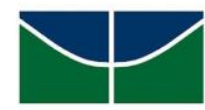

2012

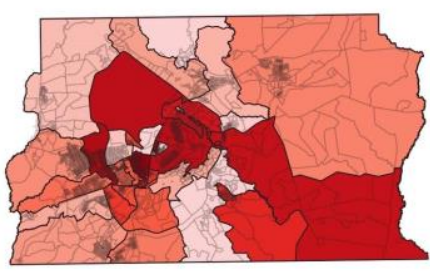

2015

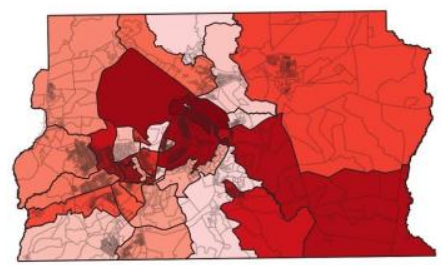

INFORMAÇÕES TÉCNICAS

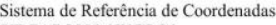
SIRGAS 2000 / WGS 84 Produzido em Novembro de 2020. Por: Ruan Italo de Araujo Guajajar Artigo: Espacialidade do HIV e da AIDS no
Distrito Federal - Período de 2012 a 2017.
Universidade de Brasilia - UnB Departamento de Geografia - GEA/UnB Trabalho de Conclusão de Curso (TCC) Discente: Ruan Italo de Araujo Guajajar Orientador: Prof. Dr. Rafael Franca Coorientadora: Prof." Dr." Marli Sales
2013

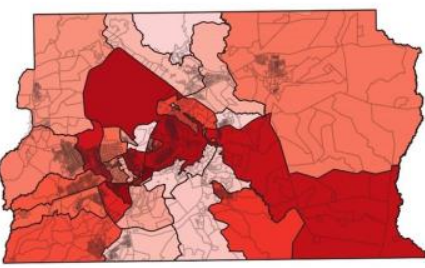

2016

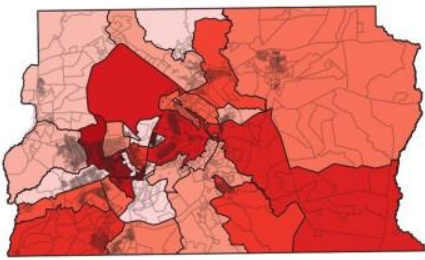

LOCALIZAÇÃo

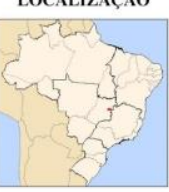

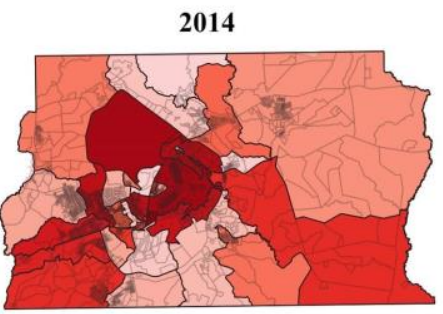

2017

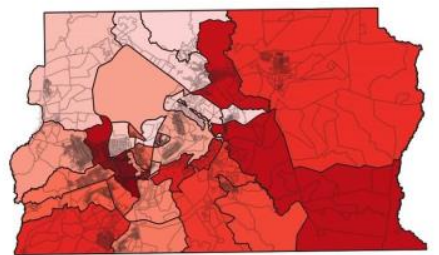

RESULTADOS

O georreferenciamento é baseado na classificação dos dados do

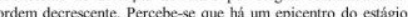
adoecimento nas regiões de Saúde Centro Sul e Central. Contudo, diferentemente do Coeficiente de Detecção de HIV, surgem nova
RA's entre as que apresentam maiores incidências de AIDS, exponencial para as bordas de DE, caracterizadas por serem regios periferizadas, como: Estrutural, Planaltina, Sobradinho periferizadas, como: Estrutural, Planaltina,
Taguatinga, Samambaia, Recanto das Emas e Gama $\begin{array}{lll}0 & 10 & 20 \mathrm{~km}\end{array}$ $\longmapsto 1$

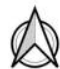

Fonte dos dados: BE de HIV/AIDS da SES - DF (2018). Produção própria. 
Em referência às tendências anuais, observa-se que há um esbranquiçamento da região central do DF, indicando uma diminuição do coeficiente de incidência por AIDS nas regiões acima discutidas. Em contrapartida, nota-se uma maior intensidade do vermelho expandindo-se para a borda do DF. Em relação à espacialidade da AIDS como um todo, percebe-se que o desenvolvimento da doença ainda se concentra nas regiões de saúde centro-sul e sudoeste, podendo revelar um epicentro, contudo, há também uma descentralização destes dados, expandindo-se para regiões mais periferizadas, indicando maior intensidade ocasional em regiões administrativas como Paranoá, Planaltina, Gama, Samambaia e Recanto das Emas.

\section{Fatores de Vulnerabilidade}

O espaço e a espacialidade da doença são resultados e condições dos processos sociais. A reprodução da AIDS pode indicar maior potencialidade em territórios administrativos distantes do centro, tornando-se visível como o fenômeno do adoecimento acontece de forma ampla no DF, alcançando as bordas, enquanto que o HIV vem se concentrando em algumas regiões, como a região de saúde centro-sul e sudoeste.

Percebe-se uma série de elementos vulnerabilizantes capazes de influenciar os processos de saúdedoença dos indivíduos, constituindo-se como um combo de vulnerabilidades às populações-chave ${ }^{7} \mathrm{e}$ aos grupos prioritários ${ }^{8}$. As diferentes potências desses elementos são capazes de promover transformações espaciais, pois, ao chegar na pessoa, em sua individualidade e no seu ser-no-mundo, a infecção por HIV ou o adoecimento por AIDS muda a forma de existir e incidir no espaço.

Construindo um raciocínio a partir da Geografia da Saúde, compreende-se que há uma possibilidade da infecção por HIV e do adoecimento por AIDS serem influenciados por fatores psicológicos, culturais e socioespaciais. Busca-se dialogar o conceito de vulnerabilidade socioambiental urbana (Mendonça, 2011) com aquilo que Santos entende como o espaço sendo uma totalidade, influenciado por processos socioespaciais (1979). Assim, o risco de infecção pelo vírus HIV e de adoecimento por AIDS não pode ser compreendido senão relacionado à totalidade do universo no qual as pessoas se encontram imersas (Paulilo, 1999, p. 22), uma vez que o desenvolvimento da AIDS apresenta uma faceta individual intrinsecamente ligada a seu processo histórico e social. A pesquisa limita-se aos boletins epidemiológicos e a uma curta série histórica de seis anos. Contudo, busca-se analisar também os elementos que alcancem a individualidade das pessoas que se encontram entre as mais vulneráveis neste processo, investigando o que os potencializa. Compreende-se que nesta etapa da pesquisa seria fundamental a aplicação de questionários para a obtenção de respostas mais subjetivas e qualitativas.

No entanto, é possível inferir elementos do processos de infecção e adoecimento, estes estando influenciados por fatores psicológicos, culturais e socioespaciais, compondo uma Tríade do processo de saúde-doença. Apresenta-se um possível modelo de elementos potencializadores de infecção por HIV e adoecimento por AIDS, conforme figura 4.

Compreende-se que o desequilíbrio entre um desses fatores poderia acentuar o processo de infecção por HIV ou adoecimento por AIDS no indivíduo, uma vez que os elementos apresentados se relacionam de forma contínua e simultânea no espaço onde a vida se dá. De forma a sintetizar as informações da tríade, foram inseridos apenas alguns elementos possíveis de se inferir, como forma de exemplificar o processo de saúde-doença.

Dentro dos fatores psicológicos destaca-se o já citado medo do diagnóstico e a saúde mental dos indivíduos. Contudo, ainda é possível inferir que a insegurança e a violência no qual essas pessoas estão submetidas seriam elementos causadores de desequilíbrios no processo de saúde-doença. Vale ressaltar a situação de moradia, de como habitam no lugar do cotidiano, se há ou não apoio, base familiar e relações de confiança.

\footnotetext{
${ }^{7}$ Gays e homens que fazem sexo com homens $(\mathrm{HSH})$, pessoas trans, pessoas privadas de liberdade, trabalhadoras (es) sexuais, bem como pessoas que usam alcóol e outras drogas. A pandemia concentra-se nestes segmentos em condição de maior vulnerabilidade, indicando uma prevalência superior à média nacional $(0,4 \%)$

${ }^{8}$ População jovem, negra, indígena e em situação de rua. Apresentam fragilidade que também os tornam mais vulneráveis. 
Figura 4 - Possível Modelo de elementos potencializadores dos processos de infecção por HIV e adoecimento por AIDS.

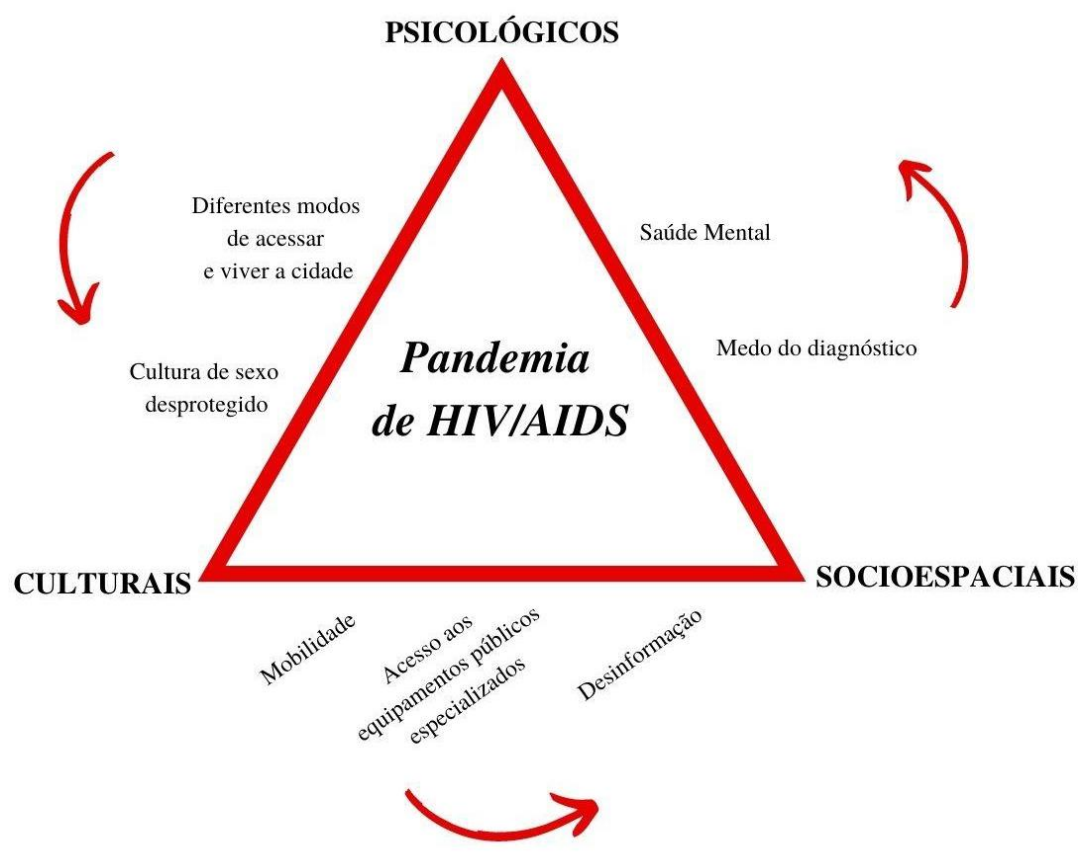

Adaptação própria com base em Paulilo (1999), Santos (1979) e Mendonça (2011).

No que diz respeito aos fatores culturais, observa-se que os diferentes modos de viver a cidade, baseado no acesso e no uso desigual do território, poderiam ser elementos capazes de influenciar os processos de saúde-doença, uma vez que diferentes grupos ocupam a cidade a partir de sua renda e classe social. Há também uma cultura do sexo desprotegido, fetichizando relações sexuais não seguras. A ampla rede tecnológica que se materializa a partir de aplicativos de relacionamento gera também uma rede de sexo, criando um movimento de acessibilização de práticas sexuais marginalizadas. Por fim, compreende-se que a ausência cultural de Educação Sexual nas escolas também tem papel fundamental neste fenômeno.

Já em relação aos fatores socioespaciais, percebe-se uma gama de elementos capazes de influenciar o processo de saúde-doença, como a urbanização excludente do DF, centralizando serviços e equipamentos públicos especializados, periferizando grupos sociais. O rápido crescimento e a concentração demográfica, também associado à intensa e desordenada urbanização, potencializa diversos tipos de adoecimento na cidade. O desemprego, as condições de alimentação e nutrição, a pobreza e os movimentos pendulares cotidianos são capazes de interferir neste processo. Cabe ressaltar a mobilidade e a precarização do transporte para acessar os serviços de prevenção e tratamento, uma vez que as tarifas são encarecidas e o direito à cidade não é assegurado. A eficiência das políticas públicas de prevenção ao HIV e a AIDS, bem como a desinformação, também precisam ser consideradas como possíveis elementos que tangenciam os processos de saúdedoença.

\section{CONCLUSÕES}

Ao espacializar as diferentes incidências de HIV e AIDS no DF, identificou-se um aumento da infecção por HIV em regiões administrativas de classe média e média baixa, com alto potencial de interação urbana, como Riacho Fundo e Guará. Já em relação à AIDS, as regiões administrativas que apresentaram maior redução se configuram como de classe média alta ou alta, indicando que o processo de adoecimento não tem acontecido com a mesma intensidade em regiões com alto índice de desenvolvimento humano, como Lago Norte, Cruzeiro e Plano Piloto. Torna-se evidente que diferentes contextos socioespaciais originam diferentes processos de saúde-doença.

O espaço urbano é diferentemente ocupado em função das classes em que se divide a sociedade, potencializando um sistema de urbanização excludente. Dessa forma, este espaço vem se tornando 
um mantenedor de desigualdades das diferentes populações, acentuando a intensidade dos processos de saúde-doença de forma diferenciada nos grupos sociais. Percebe-se que o processo de polinucleamento do DF, bem como o direito à cidade, a mobilidade e a desinformação acerca do HIV e da AIDS, seriam elementos a se aprofundar nas próximas etapas da pesquisa, a fim de responder as altas incidências em uma região e em outras não.

A pandemia de HIV e AIDS cobra um olhar estratégico da ciência geográfica. Este espaço, contendo as singularidades sociais e culturais das diversas experiências sexuais, estando conectado à uma rede heterogênea de poder, não só condiciona a disseminação do HIV, mas também condiciona quem adoece. As estruturas econômicas, sociais e políticas interferem diretamente na complexa teia que é o olhar em saúde, indicando fenômenos singulares em cada processo de adoecimento.

Entende-se também que não se pode tirar nenhuma conclusão definitiva, uma vez que a pesquisa apresenta uma séria histórica curta, de seis anos, onde o ideal seria uma série de no mínimo dez anos para criar um cenário epidemiológico representativo. Contudo, mesmo com as problematizações dessa série histórica, é possível verificar tendências, contribuindo com o monitoramento e futuras ações do Estado em relação a pandemia de HIV e AIDS.

A vigilância epidemiológica através de programas de geotecnologias é necessária para enfrentar os processos de adoecimento que estão concentrados nas cidades e nos adensamentos urbanos. As ferramentas geográficas se destacam no raciocínio em saúde, pois produz e analisa informações, elaborando procedimentos a serem implementados na rede de saúde, monitorando, orientando e fortalecendo o SUS. Portanto, torna-se fundamental produzir respostas adequadas à vulnerabilização da população, combatendo uma cadeia de transmissão do vírus e da doença a partir do contexto na qual as pessoas estão inseridas.

\section{REFERÊNCIAS BIBLIOGRÁFICAS}

ADRIANO, J. R. et al. A construção de cidades saudáveis: uma estratégia viável para a melhoria da qualidade de vida? Ciência \& Saúde Coletiva, 5(1):53-62, 2000. https://doi.org/10.1590/S1413$\underline{81232000000100006}$

BARCELLOS, Christovam: As relações entre Brasil e França na geografia da saúde: Tradições e desafios atuais. In: GURGEL, Helen; BELLE, Nayara (org.). Geografia e saúde: teoria e método na atualidade. Brasília: Universidade de Brasília, 2019. $170 \mathrm{p}$.

BARCELLOS, Christovam; BUZAI, Gustavo D.; HANDSCHUMACHER, Pascal. Geografia e saúde: O que está em jogo? História, temas e desafios. In: Confins, Revue franco-brésilienne de géographie. 2018, n. 37. Disponível em: <https://journals.openedition.org/confins/14911>. Acesso em: Novembro de 2020. https://doi.org/10.4000/confins.14954

BRASIL. Ministério da Saúde. Boletim Epidemiológico HIV/AIDS 2018. Disponível em: $<$ http://www.aids.gov.br/pt-br/pub/2018/boletim-epidemiologico-hivaids-2018. $>$ Acesso em: Março de 2020.

BRASIL. Ministério da Saúde. Boletim Epidemiológico HIV/AIDS 2019. Disponível em: $<$ http://www.aids.gov.br/pt-br/pub/2019/boletim-epidemiologico-de-hivaids-2019.> Acesso em: Março de 2020.

BRASIL. Ministério da Saúde. Agenda estratégica para ampliação do acesso e cuidado integral das populações-chave em HIV, Hepatites virais e outras infecções sexualmente transmissíveis (2018). Disponível em: <http://www.aids.gov.br/pt-br/pub/2018/agenda-estrategica-para-ampliacaodo-acesso-e-cuidado-integral-das-populacoes-chaves-em-hiv.> Acesso em: Março de 2020.

BRITO, Ana Maria de; CASTILHO, Euclides Ayres de; SZWARCWALD, Célia Landmann. AIDS e infecção pelo HIV no Brasil: uma epidemia multifacetada. Revista da Sociedade Brasileira de Medicina Tropical [online]. 2001, v. 34, n. 2, pp. 207-217. Pub: 31 Maio de 2001. ISSN 1678-9849. Disponível em: <https://doi.org/10.1590/S0037-86822001000200010>. Acesso em: Maio de 2021. https://doi.org/10.1590/S0037-86822001000200010

BATTAUS, Danila M. de Alencar; OLIVEIRA, Emerson Ademir B. de. 0 direito à cidade: Urbanização excludente e a política urbana brasileira. Lua Nova, São Paulo, n. 97, p. 81-106, 
Apr. 2016. Disponível em: <http://dx.doi.org/10.1590/0102-6445081-106/97>. Acesso em: Novembro de 2020. https://doi.org/10.1590/0102-6445081-106/97

DISTRITO FEDERAL. Subsecretaria de Vigilância à Saúde. Secretaria de Saúde - DF. Boletim epidemiológico HIV/AIDS e outras infecções sexualmente transmissíveis - IS. Ano 9, ㄲo 01, novembro de 2018. Disponível em: <http://www.saude.df.gov.br/dst-aids/>. Acesso em: Março de 2020.

DISTRITO FEDERAL. Secretaria de Estado de Desenvolvimento Urbano e Habitação. Plataforma online: Geoportal. Disponível em: <https://www.geoportal.seduh.df.gov.br/mapa/\#>. Acesso em: Março de 2020

FRANCO AGUDELO, Saúl. Momento y contexto de la violencia en Colombia. Rev Cubana Salud Pública, Ciudad de La Habana, v. 29, n. 1, p. 18-36, marzo 2003 . Disponível em: $<$ http://scielo.sld.cu/scielo.php?script=sci_arttext\&pid=S0864-

34662003000100004\&lng=es\&nrm=iso>. Acesso em: Novembro de 2020.

MELO, E. A.; MAKSUD I; AGOSTINI, R. Cuidado, HIV/Aids e atenção primária no Brasil: desafio para a atenção no Sistema Único de Saúde? Revista Panamericana Salud Publica. 2018; 42: e 151. Disponível em: <https://doi.org/10.26633/RPSP.2018.151>. Acesso em: Novembro de 2020. https://doi.org/10.26633/RPSP.2018.151

MENDES, E.V. Um novo paradigma sanitário: a produção social da saúde. 233-300. In MENDES, E.V. Uma Agenda para a Saúde. Ed. Hucitec, São Paulo. 1996.

MENDONÇA, Francisco de Assis; SOUZA, Adilson Veiga e; DUTRA, Denecir de Almeida. Saúde pública, urbanização e dengue no Brasil. Soc. nat. (Online), Uberlândia , v. 21, n. 3, p. 257-269, Dec. 2009 . Disponível em: <http://dx.doi.org/10.1590/S1982-45132009000300003>. Acesso em: Novembro de 2020. https://doi.org/10.1590/S1982-45132009000300003

MENDONÇA, Francisco. Riscos, vulnerabilidades e resiliência socioambientais urbanas: inovações na análise geográfica. Revista da ANPEGE, [S.I.], v. 7, n. 01, p. 111-118, out. 2011. ISSN 1679-768X. Disponível em: <https://ojs.ufgd.edu.br/index.php/anpege/article/view/6557/3557>. Acesso em: Novembro de 2020. https://doi.org/10.5418/RA2011.0701.0010

NOSSA, Paulo. Saúde e Espaço: Abordagem teórico-metodológica em Geografia da Saúde. Edições Afrontamento. Porto: 2014. Coleção Biblioteca das Ciências Sociais, Plural 16.

PAULILO, Maria Angela Silveira. AIDS, os sentidos do risco. São Paulo, Veras Editora, 1999.

PAVIANI, Aldo. Geografia urbana do Distrito Federal: Evolução e tendências. Brasília: 2007. Revista Espaço \& Geografia, v. 10, n. 1, 1:22. Disponível em: $<$ http://www.Isie.unb.br/espacoegeografia/index.php/espacoegeografia/article/view/61/60>. Acesso em: Novembro de 2020.

PAVIANI, Aldo. Patrimônio urbano de Brasília: urbanização com desigualdade socioespacial. 9oㅡㄴ Seminário Docomomo Brasil, 2011. Disponível em: <http://docomomo.org.br/wpcontent/uploads/2016/01/025 M01-PatrimonioUrbanoDeBrasilia ART aldo paviani-1.pdf.> Acesso em: Março de 2020.

QGIS. Org (2020), Versão 3.6.2. Sistema de Informação Geográfica QGIS. Open Source Geospatial Foundation Project.

ROJAS, Luisa Basilia Iñiguez. Geografia e saúde: o antigo, o novo e as dívidas. In: GURGEL, Helen; BELLE, Nayara (org.). Geografia e saúde: teoria e método na atualidade. Brasília: Universidade de Brasília, 2019. 170 p.

ROSA, R. e BRITO, J.L.S. Introdução ao Geoprocessamento: Sistema de Informações Geográficas. Uberlândia, 1996.

SANTOS, Milton. A Natureza do Espaço. São Paulo, Editora da Universidade de São Paulo, 1996.

SANTOS, Milton. Da Totalidade ao Lugar. São Paulo, Editora da Universidade de São Paulo, 1979.

SANTOS, Milton. Metamorfoses do Espaço Habitado. São Paulo, Editora da Universidade de São Paulo, 1988. 
SCHAEFFER, Maria de Fátima Castilhos. Segregação socioespacial no Distrito Federal. Revista KATÁLYSIS, Florianópolis, v. 6, n. 2, (2003). Disponível em: $<$ https://periodicos.ufsc.br/index.php/katalysis/article/view/7901/7309..$>$ Acesso em: Março de 2020.

STEINBERGER, Marília (org). Território, Estado e políticas públicas espaciais. Brasília: Ler Editora, 2013. 328 p. 